\title{
Diagnosis of production system of marine frozen products by inventory management theory - A case of blue fins
}

\author{
Koichi Murata ${ }^{1, ~ *, ~ N a o ~ W a t a n a b e ~}{ }^{2}$, Reakook Hwang ${ }^{3}$, Seiichiro Isobe ${ }^{1}$, Hiroshi Katayama ${ }^{4}$ \\ ${ }^{1}$ Department of Industrial Engineering and Management, College of Industrial Technology, Nihon University, Chiba, Japan \\ ${ }^{2}$ Large Motors and Drives Department, Discrete Automation and Motion Division, ABB K.K., Tokyo, Japan \\ ${ }^{3}$ Industry \& Strategy Department I, Samsung Economic Research Institute, Seoul, Korea \\ ${ }^{4}$ Department of Industrial and management Systems Engineering, Faculty of Science and Engineering, Waseda University, Tokyo, Japan
}

\section{Email address:}

murata.kouichi30@nihon-u.ac.jp (K. Murata)

\section{To cite this article:}

Koichi Murata, Nao Watanabe, Reakook Hwang, Seiichiro Isobe, Hiroshi Katayama. Diagnosis of Production System of Marine Frozen Products by Inventory Management Theory - A Case of Blue Fins. International Journal of Intelligent Information Systems. Special Issue: Logistics Optimization Using Evolutionary Computation Techniques. Vol. 4, No. 2-1, 2015, pp. 18-24.

doi: 10.11648/j.ijiis.s.2015040201.14

\begin{abstract}
The purpose of this paper is a characteristic analysis of current production and inventory system for frozen products of blue fins under a fishery instability caused by the warming of the earth and an indiscriminate fishing. For the analysis, a simulation is performed quoted by Vassian's production management theory. The result of the analysis is that the current system is aimed at minimizing a variation of the inventory at the end of the period.
\end{abstract}

Keywords: Production and Inventory Planning System, Frozen Processing Industry, Simulation

\section{Introduction}

This paper proposes a simple diagnosis of current capability of actual production system by an inventory management theory. Objective system is a production system of blue fins frozen products in Japan. The reason is that Japan has the largest fishing and consumptions of them in the world. However a catch of blue fins has been decreased these past few years because of the warming of the earth and an indiscriminate fishing. Also, after 2011 Tohoku earthquake and tsunami, a development of a renewal production model has been required in the area. Applied theory is Vassian's production management theory (1954) which is one of the traditional and robust theories. It is mainly used to decide a production order with considering an inventory of the product. In this paper, an application of the theory is performed to check a capability of current production system. The challenge of this paper has two meaning. First, a use of the theory will be expanded from a determination of a production order to a diagnosis of a current production system. Second, a convenient method based on a theoretical approach is proposed to an actual production site for an intermediation between an academic field and an industry field.

\section{Literature Review}

Simon proposed one inventory management models by a servomechanisms theory. One of them is illustrated from Figure 1 (Simon 1952). It is a feedback control system by the block system. The optimum inventory $\theta_{I}$ is input data, the actual inventory $\theta_{o}$ is output data and the difference between two data $\varepsilon\left(=\theta_{I}-\theta_{o}\right)$ is an error. An order $\theta_{L}$ is a disturbance of warehouse $K_{l}$ as a controlled object. An inventory controller $K_{2}$ determines a manipulated variable $\mu$ to minimize the difference $\varepsilon$ and supplies to warehouse $K_{l}$.

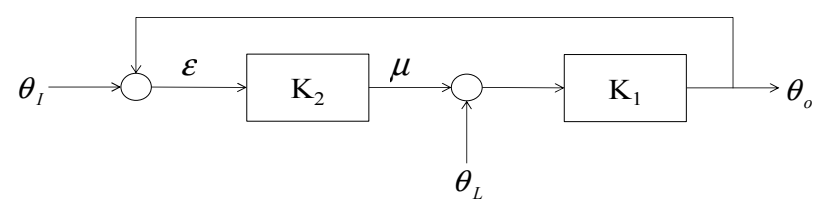

Figure 1. Inventory Management System (Simon 1952)

There have been researches about the production and inventory planning based on the model. He himself introduced a fixed interval ordering system in which production lead time was adapted to a manipulated variable $\mu$ of the model (Simon 1952). Vassian (1954) proposed a fixed interval ordering system 
quoted by a control theory too. In the model, a demand at period $t$ is input and an inventory at the end of the period $t$ is output. By the two assumptions, a block diagram can express the manufacturing flow which is an order, a production and an inventory in order. Equation (1) and Equation (2) are a mathematical model of the diagram. Equation (1) has four items such as a) accumulated demands predicated within next production lead time, b) production orders delivered for the future, c) inventories at the end of the period and d) safety inventories. The output is a production order of each period to minimize the variation of the inventory at the end of the period.

$$
\begin{gathered}
P_{t}=\sum_{i=1}^{L} \widehat{D}_{t ; t+i}+\sum_{i=1}^{L-1} P_{t-i}-I_{t}+S \\
I_{t}=I_{t-1}+P_{t-L}-D_{t}
\end{gathered}
$$

$<$ Notation $>$

$D_{t}$ : Demand at the period $t$

$I_{t}$ : Inventory at the end of the period $t$

$P_{t}$ : Production order indicated at the period $t$. It is delivered at the period $t+L$.

$\widehat{D}_{t ; t+i}$ : Future demand at the period $t+i$ predicated at the end of the period $t$

L: Production lead time+1

S: Safety inventory

Furthermore various studies have been performed based on Vassian's model. For example, Katayama (1986, 1998) and Nishijima (1999) developed sub-models of the model, i.e. methodologies of a demand forecasting or a production ordering. Hirakawa (2003) extended the model to a multistep system. These outputs are mainly applied to manufacturing industry. In addition, an application range of the studies has been spread in recent year. For example, Chiyoma (2013) utilized Vassian's model to a supply chain on agriculture industry. All investigated studies are only used to decide a production order as a matter of course. An idea of this study is that a decision model of a production order is used to diagnosis a type of a production system.

On the other hand, in this paper, a marine frozen production industry is focused. As for the industry, Pall (1988) is recognized as one of the previous studies. Focusing on a procurement activity of a processing factory under the influence of daily variation of fish catches in north Europe, it proposes a formularization of a production scheduling problem under the condition of the effect by linear programming. However, studies of a marine frozen production by the approach from a production management are not found except it under reviewing related literature up to the present.

\section{Research Procedure}

Research procedure of this paper consists of the four steps.

\subsection{STEP1: Investigation of Statistical Data}

From the annual report of statistical data on a distribution of aquatic products (Ministry of Agriculture, Forestry and Fisheries 2007, 2008, 2009, 2010 and 2012), three statistical data on a frozen production of blue fins, as the object of our research, are surveyed such as 1) a monthly amount of materials to plants, 2) a monthly amount of products from plants and 3) an inventory of products at the end of the month. The report is the result of the survey on a distribution of frozen aquatic products in the survey on a distribution of aquatic products. It is carried out by Ministry of Agriculture, Forestry and Fisheries in Japan. The object data of this paper are data from 2005 to 2009 before not only a modification of how to survey from 2010 but also the 2011 earthquake off the Pacific coast of Tohoku. A definition of blue fins is followed by the annual report. Namely, the category of blue fins consists of four kinds such as a long-finned tuna, a big eye tuna, a yellow fin tuna and others.

In order to analyze surveyed data, not only basic statistics but also a link relative is calculated to a monthly amount of materials to plants and a monthly amount of products from plants. Values of a link relative are given in the utilization process of a method of a link relative (Persons 1919). It is the ratio of each item at the period $t$ of the series to the preceding item, which is item at the period $t-1$. A quantification of a change of an annual series' shape of the two surveyed data will be expected by the indicator.

\subsection{STEP2: Construction of Constructed Models}

Two constructed models are formularized to grasp the current of the object system. Previously, a performance of a production and inventory planning system is measured by a stability of input and/or output of the system. A representative indicator of the former is a variation of an indicated production order and that of the latter is a variation of an inventory at the end of the period (Nishijima 1999). Watanabe (2013) focuses on the facts and proposes a method to analyze the characteristic of the current system through the comparison among the current system, the model to minimize a variation of an indicated production order and the model to minimize a variation of an inventory at the end of the period. This paper applies to the analysis method too.

\subsection{STEP3: Simulation of Production and Inventory System}

In the simulation, a monthly amount of materials to plants investigated in Step 1 is considered as input data of two models constructed in Step 2. And an average and a standard deviation of an indicated production order and an inventory at the end of the period are calculated in the simulations by every model. Through the comparisons among current values and the results, a characteristic of the current system is analyzed.

\subsection{STEP4: Discussion}

Based on the result in the previous steps, the future direction of a production and inventory planning system of frozen blue fins products is discussed. 


\section{STEP1: Investigation of Statistical Data}

\subsection{A Monthly Amount of Materials to Plants}

Figure 2 shows time series of a monthly amount of materials to plants from 2005 to 2009 . It is found that the time series go down year by year. In particularly, the minimum amount is reduced every year. An average of the monthly amounts is 31,545 ton in 2009 which is $88 \%$ of 38,322 ton in 2005.

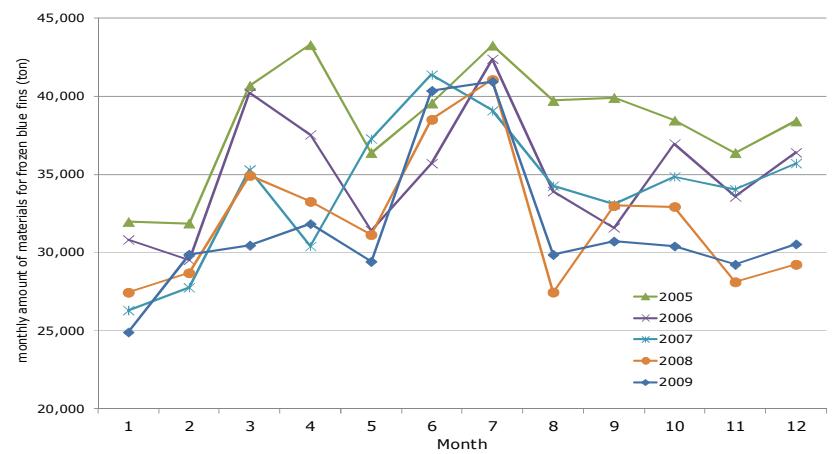

Figure 2. Time series of monthly amount of materials for frozen blue fins from 2005 to 2009

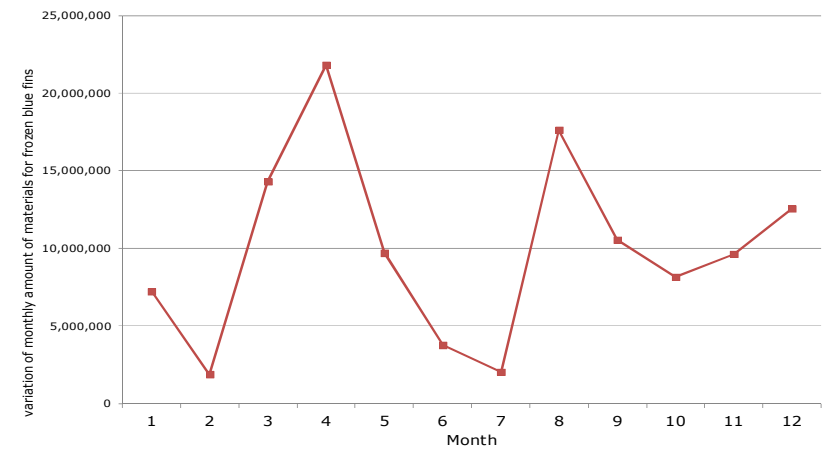

Figure 3. Time series of variation of monthly amount of materials for frozen blue fins among five years from 2005 to 2009

Table 1. Link relatives of monthly amount of materials for frozen blue fins from 2005 to 2009

\begin{tabular}{|c|c|c|c|c|c|}
\hline Month & 2005 & 2006 & 2007 & 2008 & 2009 \\
\hline 1 & - & 0.80 & 0.72 & 0.77 & 0.85 \\
\hline 2 & 1.00 & $0.96^{*}$ & $1.06^{* *}$ & 1.05 & 1.20 \\
\hline 3 & 1.28 & 1.36 & 1.27 & 1.22 & 1.02 \\
\hline 4 & 1.06 & $0.93 \%$ & 0.86 & 0.95 & $1.05^{* \%}$ \\
\hline 5 & 0.84 & 0.84 & $1.23^{* *}$ & $0.94 \%$ & 0.92 \\
\hline 6 & 1.09 & 1.14 & 1.11 & 1.24 & 1.37 \\
\hline 7 & 1.09 & 1.19 & $0.94^{*}$ & $1.07^{* \%}$ & 1.01 \\
\hline 8 & 0.92 & 0.80 & 0.88 & 0.67 & 0.73 \\
\hline 9 & 1.00 & $0.93 \%$ & 0.97 & $1.20 \%$ & 1.03 \\
\hline 10 & 0.96 & $1.17^{* \%}$ & 1.05 & 1.00 & $0.99^{*}$ \\
\hline 11 & 0.95 & 0.91 & 0.98 & 0.85 & 0.96 \\
\hline 12 & 1.06 & 1.08 & 1.05 & 1.04 & 1.04 \\
\hline
\end{tabular}

There are some months which have large variation of the monthly amounts among five years. In particularly, the amounts on April and August in 2009 drop to a lower position but the amounts in 2005 are the most of amounts in five years. From the results, the variation of the monthly amount on each month is very large as shown in Figure 3.

Furthermore, Table 1 indicates link relatives every month among five years. It is found that a change of increase or decrease of the amount at a month against the amount at next month occurs during the investigated years.

Instability of the amount is confirmed based on the above analysis. A realization of maintenance of a capacity of a frozen processing line to overcome the burden will be needed.

\subsection{A Monthly Amount of Frozen Products from Plants}

Figure 4 show time series of a monthly amount of products from plants from 2005 to 2009. It is found that the time series go down year by year like a monthly amount of materials to plants. An average of the monthly amounts is 38,224 ton in 2009 which is $85 \%$ of 32,365 ton in 2005 . On the other hand, in comparison with the time series among five years, there is little disturbance of the shape of the time series. From Table 2, it indicates to realize steady supply to the market every year. However, in case of July, a change of increase or decrease of the amount at a month against the amount at next month occurs during the investigated years.

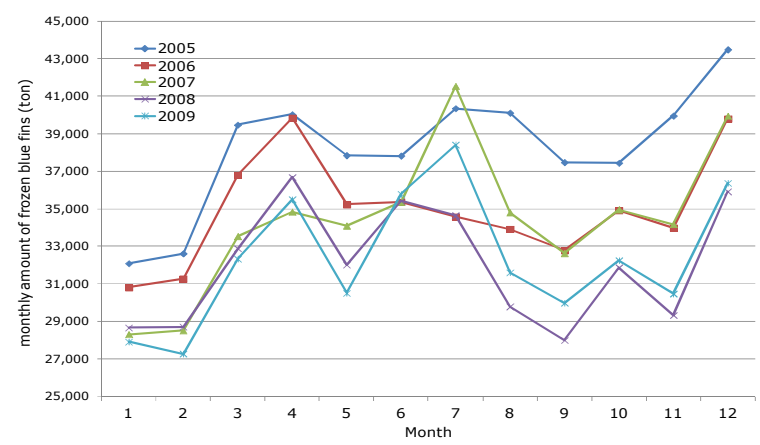

Figure 4. Time series of monthly amount of frozen blue fins from 2005 to 2009

Table 2. Link relatives of monthly amount of frozen blue fins from 2005 to 2009

\begin{tabular}{llllll}
\hline Month & $\mathbf{2 0 0 5}$ & $\mathbf{2 0 0 6}$ & $\mathbf{2 0 0 7}$ & $\mathbf{2 0 0 8}$ & $\mathbf{2 0 0 9}$ \\
\hline 1 & - & 0.71 & 0.71 & 0.72 & 0.78 \\
2 & 1.02 & 1.01 & 1.01 & 1.00 & $0.98 \%$ \\
3 & 1.21 & 1.18 & 1.18 & 1.15 & 1.19 \\
4 & 1.01 & 1.08 & 1.04 & 1.12 & 1.10 \\
5 & 0.95 & 0.88 & 0.98 & 0.87 & 0.86 \\
6 & 1.00 & 1.00 & 1.04 & 1.11 & 1.17 \\
7 & 1.07 & $0.98 \%$ & $1.18 \% *$ & $0.98 \%$ & $1.07 \%$ \\
8 & 0.99 & 0.98 & 0.84 & 0.86 & 0.82 \\
9 & 0.93 & 0.97 & 0.94 & 0.94 & 0.95 \\
10 & 1.00 & 1.07 & 1.07 & 1.14 & 1.08 \\
11 & 1.07 & $0.97 \%$ & 0.98 & 0.92 & 0.94 \\
12 & 1.09 & 1.17 & 1.17 & 1.22 & 1.19 \\
\% : A link relative is less than 1.00 at a year but it is 1.00 and over at the \\
preceding year. \\
\% : A link relative is 1.00 and over at a year but it is less than 1.00 at the \\
preceding year.
\end{tabular}


In the tendency of quantitative reduction mentioned above, a ratio of a setup time to total processing time will be increased. It is necessary to maintain a productivity of a production system which is equal to the conventional system.

\subsection{An Inventory of Products at the End of the Month}

Figure 5 shows time series of an inventory of products at the end of the month from 2005 to 2009. It is found that the time series go down year by year like two kinds of the amounts mentioned above. Days of an inventory are illustrated from Figure 3. It is given a monthly amount of the products from plants divided by an inventory of the products at the end of the month. An average of the indicator increases from 1.77 in 2005 to 1.95 in 2009 . It seems that a suitable reduction of an inventory of the products has not been performed. Furthermore a variance of the indicator increases from 0.22 in 2005 to 0.05 in 2009 . It indicates the instability of the inventory of the products.

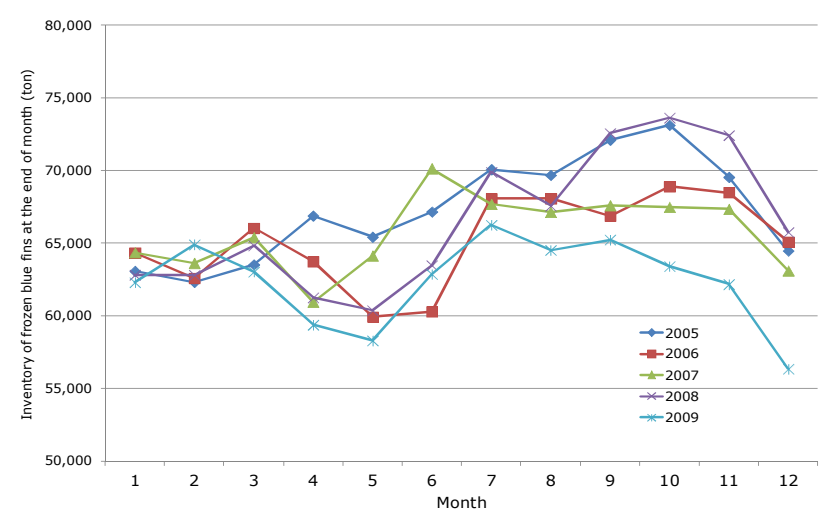

Figure 5. Time series of inventory of frozen blue fins at the end of month from 2005 to 2009

Table 3. Days of an inventory of frozen blue fins from 2005 to 2009 (Month)

\begin{tabular}{llllll}
\hline Month & $\mathbf{2 0 0 5}$ & $\mathbf{2 0 0 6}$ & $\mathbf{2 0 0 7}$ & $\mathbf{2 0 0 8}$ & $\mathbf{2 0 0 9}$ \\
\hline 1 & 1.97 & 2.09 & 2.27 & 2.19 & 2.23 \\
2 & 1.91 & 2.00 & 2.23 & 2.19 & 2.38 \\
3 & 1.61 & 1.80 & 1.95 & 1.97 & 1.95 \\
4 & 1.67 & 1.60 & 1.75 & 1.67 & 1.67 \\
5 & 1.73 & 1.70 & 1.88 & 1.89 & 1.91 \\
6 & 1.78 & 1.71 & 1.98 & 1.79 & 1.76 \\
7 & 1.74 & 1.97 & 1.63 & 2.02 & 1.73 \\
8 & 1.74 & 2.01 & 1.93 & 2.27 & 2.04 \\
9 & 1.92 & 2.04 & 2.07 & 2.59 & 2.18 \\
10 & 1.95 & 1.97 & 1.93 & 2.31 & 1.97 \\
11 & 1.74 & 2.02 & 1.97 & 2.47 & 2.04 \\
12 & 1.48 & 1.64 & 1.58 & 1.83 & 1.55 \\
Average & 1.77 & 1.88 & 1.93 & 2.10 & 1.95 \\
Variance & 0.020 & 0.029 & 0.040 & 0.074 & 0.055 \\
\hline
\end{tabular}

\section{STEP2: Construction of Constructed Models}

On the assumption that production lead time is one period, Equation (1) and Equation (2) become Equation (3) and
Equation (4). Two models are proposed based on the two equations. In addition, followed by the situation of the object case, $P_{t}$ means a monthly amount of materials to plants and $D_{t}$ means regarded as a monthly amount of products from plants.

$$
\begin{gathered}
P_{t}=\hat{D}_{t ; t+1}+\hat{D}_{t ; t+2}-P_{t-1}-I_{t}+S \\
I_{t}=I_{t-1}+P_{t-2}-D_{t}
\end{gathered}
$$

1) In case of a minimization of a variation of an inventory at the end of the period

The assumption that a monthly amount of products of term $i$ ahead are given at the end of the period $t$ is installed to Equation (3).

$$
\begin{aligned}
& \hat{D}_{t ; t+1}=D_{t+1} \\
& \hat{D}_{t ; t+2}=D_{t+2}
\end{aligned}
$$

2) In case of a minimization of a variation of an indicated production order

The assumption that a monthly amount of products of each period is constant is installed to Equation (3).

$$
P_{t}=C
$$

\section{STEP3: Simulation of Production and Inventory System}

\subsection{Precondition}

In this step, the simulation is performed by the two proposed models. An outline of the simulation is as follows.

$<$ Outline of the simulation $>$

- Input data: Actual data of the monthly amount of materials to plants

- Output data 1: Average and standard deviation of monthly amounts of materials

- Output data 2: Average and standard deviation of inventories at the end of month

- A number of simulation: Five times (from 2005 to 2009)

- Others

- An inventory at the end of December in the preceding year: Actual data (In case of 2005, 2004's value is utilized.)

- A monthly amount of materials to plants at November and December in the preceding year: Actual data (In case of 2005, 2004's value is utilized.)

- A monthly amount of frozen products from plants in January and February of the next year: Actual data (In case of 2009, the following equation is utilized.)

- The amount at January in $2010=$ The amount at January in $2009 \times$ (The amount at January in 2009The amount at January in 2005) $\div 5$

- The amount at February in $2010=$ The amount at February in $2009 \times$ (The amount at February in 2009- The amount at February in 2005) $\div 5$ 
- Safety inventory:

Two month's average of actual monthly amount of products from plants during simulation term

- In case of minimization of a variance of a monthly amount of materials to plants, a monthly amount of materials to plants:

Average of actual monthly amount of materials to plants during simulation term

\subsection{Results}

The results of the simulation are illustrated from Table 4, Table 5, Figure 6 and Figure 7. It is found that the current system is nearly a system to minimize a variance of an inventory at the end of the period. However it is considered that the system had a margin for a reduction of an inventory at the end of the period.

Table 4. Results of the simulation (Materials to plants)

\begin{tabular}{|c|c|c|c|c|c|c|}
\hline \multirow[t]{2}{*}{ Year } & \multicolumn{2}{|c|}{$\begin{array}{l}\text { Minimization of a variance of an inventory } \\
\text { at the end of the period }\end{array}$} & \multicolumn{2}{|c|}{ Current system } & \multicolumn{2}{|c|}{$\begin{array}{l}\text { Minimization of a variance of an amount } \\
\text { of materials to plants }\end{array}$} \\
\hline & Average & Standard deviation & Average & Standard deviation & Average & Standard deviation \\
\hline 2005 & 37,166 & 1,211 & 38,322 & 1,021 & 38,224 & 0 \\
\hline 2006 & 33,892 & 1,044 & 35,002 & 1,086 & 34,940 & 0 \\
\hline 2007 & 33,647 & 1,324 & 34,119 & 1,202 & 34,390 & 0 \\
\hline 2008 & 30,850 & 1,236 & 32,147 & 1,214 & 31,990 & 0 \\
\hline 2009 & 31,940 & 1,060 & 31,545 & 1,263 & 32,365 & 0 \\
\hline
\end{tabular}

Table 5. Results of the simulation (Inventory at the end of the period)

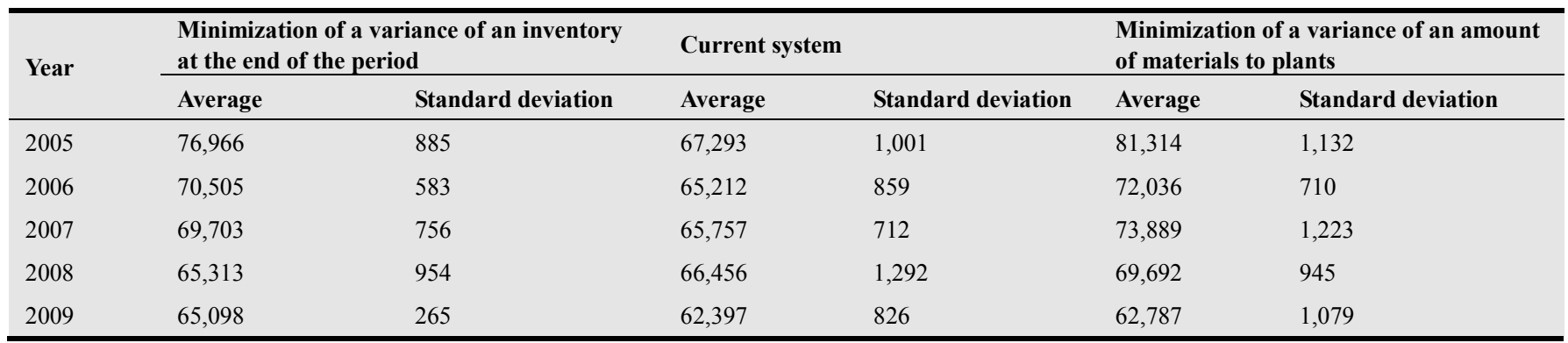

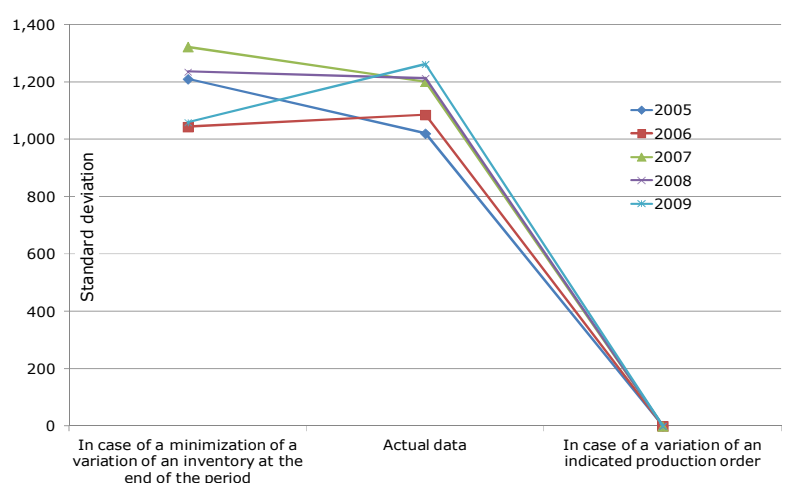

Figure 6. Standard divisions of materials of conventional model and two proposed models

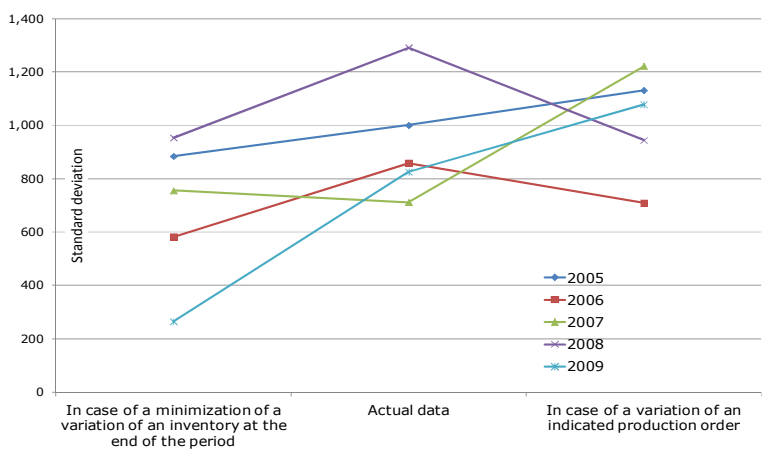

Figure 7. Standard divisions of inventories at the end of the period of conventional model and two proposed models

\section{STEP4: Discussion}

From the both results of the survey described in Step 2 and the simulation performed in Step 3, the following four future works are considered.

- Future work 1: Construction of the production system that absorbs an instability of amounts of materials to plants

- Future work 2: Improvement of a flexibility of the production line that corresponds to a reduction of amount of products from plants

- Future work 3: Compression of an inventory that corresponds to a reduction of amount of products from plants

- Future work 4: Equalization of two variances of amount of materials to plants and an inventory at the end of the period

For the first work, the amount of materials to plants is reduced and the expected amount will not be guaranteed on the basis of a stable fish catch. It is related to an excess and a deficiency of production capacity and become factors in an occurrence of opportunity loss and surplus cost. A shift of planned procurement of materials will be needed corresponding to market requirements.

For the second work, as a production scale become down, a ratio of setup time to total processing time will become up. Based on the internet survey about a frozen processing process 
of blue fins, in order to fillet one big blue fins to a shape of rectangles, several cutting process which are from a cutting of helmet-shaped head of blue fins to a removal of dark-colored meat is passed as shown in Figure 8 (Fukuichi Gyogyo 2014). An exchange time of a cutting tool is a stop time of production. It is important to shorten set up time in the process.

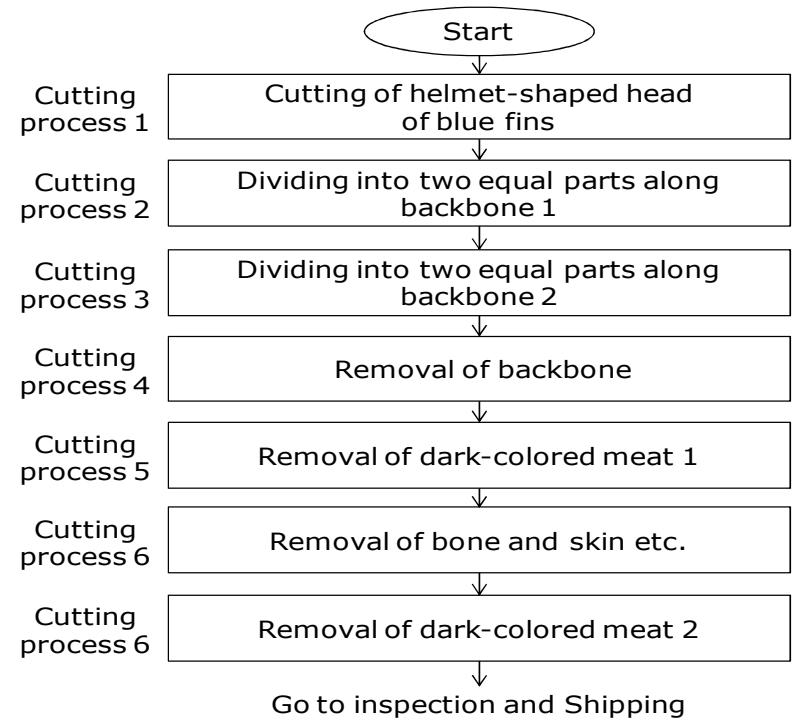

※ Authors is made referred to Fukuichi Gyogyo (2014)

Figure 8. Cutting Process in blue fins processing

For the third work, in the survey of Step 2, a reduction ratio of an inventory at the end of the period is low against a reduction ratio of amount of materials/product to/from plants. Also, it is found that a variance of an inventory at the end of the period is increasing. In general, a surplus of an inventory becomes an increase factor of cost. Accordingly effective management of an inventory in the object system will seem needed.

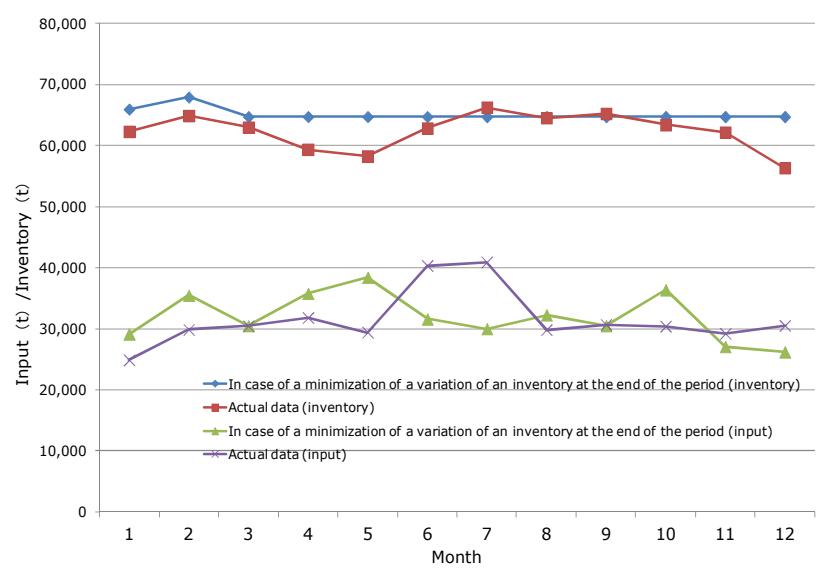

Figure 9. Time series of an amount of materials to plants and inventories at the end of the period (In case of 2009)

For the fourth work, Figure 9 shows time series of the monthly amount of materials to plants and an inventory at the end of the period provided from the simulation results described in Step 3. In case of a minimization of a variance of an inventory at the end of the period, a stationary state is kept in an inventory at the end of the period from March to December however transient characteristics are confirmed at January and February. Compared the simulated data with actual data, actual data is equal to or lower than the simulated data. On the other hand, as stated above, a variance of an inventory at the end of the period is increasing year by year. When an amount of materials to plants is checked, equalization of simulation results is better than that of actual data. Based on the results, a control of a variance of materials to plants is needed as one direction of the object system improvement. And a production and inventory system is more stabilized without becoming worse of current level of a variance of an inventory at the end of the period.

\section{Concluding Remarks}

In this paper, a characteristic analysis of current production and inventory planning system for frozen products of blue fins is performed under the instability of the fishery caused by the warming of the earth and an indiscriminate fishing. For the results, it is found that the current system is aimed at minimizing a variation of the inventory at the end of the period. Also, in order to correspond to the instability of a material procurement, the future works are discussed. For example, it is necessary to control a variance of amount of materials to plants and to reduce setup time, in particular an exchange of cutting tool, in total processing time without becoming worse of current level of a variance of an inventory at the end of the period.

\section{References}

[1] Chiyoma, H. and Katayama, H., 2013. "Model Building and Performance Analysis of Forward / Reverse: - Combined Logistics System in Agricultural Industry", Proceedings of the 8th International Congress on Logistics and SCM Systems (ICLS2013), pp. 281-288, International Conference Center of Waseda University, Tokyo, Japan, 5th-7th August.

[2] Fukuichi Gyogyo Co. Ltd. Homepages, URL: http://www.maguro-fukuboh.jp/ (Access dat: 8th, April, 2014.)

[3] Herbert A. Simon, 1952. "On the Application of Servomechanism Theory in the Study of Production Control", Econometrica, Vol. 20, No. 2, pp. 247-268.

[4] Herbert J. Vassian, 1954. "Application of Discrete Variable Servo Theory to Inventory Control", Journal of the Operations Research Society of America, Vol. 3, Iss. 3, pp. 272-282.

[5] Hirakawa Y., Katayama, H., Hoshino K. and Soshiroda M., 2003. "A Hybrid Push/Pull Production Control System for Multistage Manufacturing Environments", The Journal of The Japan Industrial Management Association, Vol. 45, No. 3, pp. 194-201.

[6] Katayama, H., 1986. "On an Ordering System Using Orthogonal Elements of Moving Average Demand Model", The Journal of The Japan Industrial Management Association, Vol. 37, No. 2, pp. 73-79. 
[7] Katayama, H., Soshiroda M. and Muramatsu R., 1988, "Analysis of Periodic Reordering System with Plural Moving Average Demands", The Journal of The Japan Industrial Management Association, Vol. 39, No. 4, pp. 218-225.

[8] Nishijima J., Goto M. And Tawara N., 1999, "A Study of Periodical Ordering System to Control the Cost Occurred from Variances", The Journal of The Japan Industrial Management Association, Vol. 50, No. 4, pp. 207-215.

[9] Ministry of Agriculture, Forestry and Fisheries, 2007. The annual report of statistical data on a distribution of aquatic products (2007), Association of Agriculture and Forestry: Tokyo.

[10] Ministry of Agriculture, Forestry and Fisheries, 2008. The annual report of statistical data on a distribution of aquatic products (2008), Association of Agriculture and Forestry: Tokyo.

[11] Ministry of Agriculture, Forestry and Fisheries, 2009. The annual report of statistical data on a distribution of aquatic products (2009), Association of Agriculture and Forestry: Tokyo.
[12] Ministry of Agriculture, Forestry and Fisheries, 2010. The annual report of statistical data on a distribution of aquatic products (2010), Association of Agriculture and Forestry: Tokyo.

[13] Ministry of Agriculture, Forestry and Fisheries, 2012. The annual report of statistical data on a distribution of aquatic products (2012), Association of Agriculture and Forestry: Tokyo.

[14] Pall J., 1988. "Daily Production Planning in Fish Processing Firms", European Journal of Operational Research, Vol. 36, pp. 410-415.

[15] Warren M. Persons, 1919. "Indices of Business Conditions", The Review of Economic Statistics, pp. 18-31.

[16] Watanabe, N., Hwang R. K. and Katayama, H., 2013. “Analysis and Improvement of Production and Inventory Planning System for Process Industry", Proceedings of The 16th Japan Society of Logistics Systems (JSLS) National Conference, pp. 91-96, Nihon University, Narashino, Chiba, Japan, 11th-12th, May. 